\title{
Germline mutations and genotype-phenotype correlation in Asian Indian patients with pheochromocytoma and paraganglioma
}

\author{
Reshma Pandit', Kranti Khadilkar', Vijaya Sarathi², Rajeev Kasaliwal ${ }^{3}$, \\ Manjunath Goroshi', Shruti Khare', Sandhya Nair', Vijaya Raghavan', \\ Abhay Dalvi", Priya Hira5, Gwendolyn Fernandes ${ }^{6}$, Pragati Sathe $^{6}$, Amey Rojekar6, \\ Gaurav Malhotra7, Ganesh Bakshi ${ }^{8}$, Gagan Prakash ${ }^{8}$, Anil Bhansali ${ }^{9}$, Rama Walia9, \\ Sadishkumar Kamalanathan ${ }^{10}$, Jayaprakash Sahoo ${ }^{10}$, Ankush Desai ${ }^{11}$, Nikhil \\ Bhagwat ${ }^{12}$, Prashanth Mappa ${ }^{13}$, Rajesh Rajput ${ }^{14}$, Sudha Rao Chandrashekhar15, \\ Vyankatesh Shivane', Padma Menon', Anurag Lila', Tushar Bandgar' ${ }^{1}$ and \\ Nalini Shah' \\ 1Department of Endocrinology, Seth G S Medical College and KEM Hospital, Mumbai, Maharashtra, India, \\ ${ }^{2}$ 2Department of Endocrinology, Vydehi Institute of Medical Sciences and Research Centre, Bangalore, Karnataka, \\ India, ${ }^{3}$ Department of Endocrinology, Mahatma Gandhi Hospital and Medical College, Jaipur, Rajasthan, India, \\ ${ }^{4}$ Departments of General Surgery, ${ }^{5}$ Radiology and ${ }^{6}$ Pathology, Seth G S Medical College and KEM Hospital, \\ Mumbai, Maharashtra, India, ${ }^{7}$ Radiation Medicine Centre, Bhabha Atomic Research Centre, Mumbai, Maharashtra, \\ India, ${ }^{8}$ Department of Uro-oncology, Tata Memorial Hospital, Mumbai, Maharashtra, India, ${ }^{9}$ Department of \\ Endocrinology, Postgraduate Institute of Medical Education \& Research (PGIMER), Chandigarh, India, \\ ${ }^{10}$ Department of Endocrinology, Jawaharlal Institute of Postgraduate Medical Education \& Research (JIPMER), \\ Pondicherry, India, ${ }^{11}$ Endocrine Unit, Department of Medicine, Goa Medical College, Bambolim, Goa, India, \\ ${ }^{12}$ Department of Endocrinology, Topiwala National Medical College \& BYL Nair Charitable Hospital, Mumbai, \\ Maharashtra, India, ${ }^{13}$ Department of Medicine, Kannur Medical College and Hospital, Kannur, Kerala, India, \\ ${ }^{14}$ Department of Endocrinology, Pt. B.D. Sharma PGIMS, Rohtak, Haryana, India, and ${ }^{15}$ Division of Pediatric \\ Endocrinology, Bai Jerbai Wadia Hospital for Children, Mumbai, Maharashtra, India
}

Correspondence should be addressed to R Pandit Email reshmap9@gmail.com

The authors apologise for an error in Table 2 of this article published in the October 2016 issue (Vol 175 pp 311-323). For Patient 6, the nucleotide change presented in column 7, should read as c.277T>G and not as published. The authors regret this error.

๑) 2016 European Society of Endocrinology Printed in Great Britain
Published by Bioscientifica Ltd. 